\title{
LA VIOLENCIA CONTRA LAS MENORES QUE INICIAN SU \\ TRAYECTORIA VITAL EN SITUACIÓN DE VULNERABILIDAD SOCIAL
}

\author{
VIOLENCE AGAINST MINORS WHO BEGIN THEIR LIFE TRAJECTORY \\ IN THE SITUATION OF SOCIAL VULNERABILITY
}

\author{
Gabriela Moriana Mateo \\ Universidad de Valencia. España/Spain \\ gabriela.moriana@uv.es
}

Recibido/Received: 20/07/2015

Modificado/Modified: 29/09/2015

Aceptado/Accepted: 04/10/2015

\section{RESUMEN}

Este artículo desvela los tipos de violencia que sufrieron las mujeres institucionalizadas cuando eran menores de edad. Las técnicas de investigación utilizadas han sido de índole cualitativa. Se ha realizado observación participante $\mathrm{y}$, a través de informes sociales, documentos personales, entrevistas informales y en profundidad, se han elaborado quince historias de vida de las mujeres que han residido en los centros de protección de la Comunidad Valenciana entre los años 1999 y 2012. Esta aproximación se centra en las ocho que iniciaron su trayectoria vital en la situación de vulnerabilidad. Los resultados muestran que las menores han sufrido distintos tipos de violencia. Una de las principales conclusiones es que la exclusión social y la violencia contra las mujeres están estrechamente relacionadas, la primera las convierte en vulnerables a la segunda y ésta, a su vez, las aboca a importantes procesos de exclusión social.

\section{PALABRAS CLAVE}

Institucionalización de mujeres, exclusión social, menores vulnerables, violencia contra las menores, violencia contra las mujeres.

\section{SUMARIO}

1. Introducción. 2. Material y método. 3. Resultados. 4. Discusión. 5. Conclusiones. Bibliografía.

\begin{abstract}
This paper shows the types of violence experienced by institutionalized women when they were minors. The main research techniques used are of a qualitative nature. Using participant observation and social reports, personal documents and in-depth informal interviews, we compiled fifteen life histories of women in processes of social exclusion who lived in women's shelters in the Valencian Community between 1999 and 2012, although this approximation focuses only on the eight that began their life trajectories in situations of vulnerability. The results show that minors suffered various types of violence. One of the main conclusions of the study is that social exclusion and violence against women are closely related. The former makes women vulnerable to the latter, and the latter in turn propels them towards processes of social exclusion.
\end{abstract}

\section{KEYWORDS}

Women's institutionalization, social exclusion, vulnerable minors, violence against minors, violence against women. 


\section{CONTENTS}

1. Introduction. 2. Material and method. 3. Results. 4. Discussion. 5. Conclusions. References.

\section{INTRODUCCIÓN}

Este artículo es fruto de un trabajo de campo etnográfico realizado en distintos centros residenciales de Servicios Sociales Especializados de Mujeres o centros protección de mujeres de la Comunidad Valenciana. Conformó la base de mi doctorado en estudios de género y la parte más importante de la tesis doctoral sobre los procesos de exclusión social y violencia contra las mujeres institucionalizadas (Moriana, 2014), temática en la que sigo reflexionando e investigando. Su objetivo es desvelar los tipos de violencia que sufrieron cuando eran menores de edad, es decir antes de los 18 años, las mujeres institucionalizadas que iniciaron su trayectoria vital en el espacio de vulnerabilidad.

Para la Organización Mundial de la Salud (2002), la violencia contra las/os menores es "cualquier forma de daño físico y/o emocional, abuso sexual, negligencia o cualquier forma de trato negligente, comercial u explotación, que resulta en el daño actual o potencial a la salud, sobrevivencia o desarrollo de la dignidad, en el contexto de una relación de responsabilidad, confianza o poder". Por su parte, la Convención de los Derechos de los Niños de la ONU (1989), la define como "toda violencia, perjuicio o abuso físico o mental, descuido o trato negligente, malos tratos o explotación, mientras que el niño se encuentre bajo la custodia de sus padres, de un tutor o de cualquier otra persona que le tenga a su cargo". En el contexto estatal y concretamente para el Ministerio de Trabajo y Asuntos Sociales (2006), la violencia contra los/os niños/as es la acción, omisión o trato negligente, no accidental, que priva al niño o la niña de sus derechos y su bienestar, que amenaza y/o interfiere su ordenado desarrollo físico, psíquico y/o social y cuyos autores pueden ser personas, instituciones o la propia sociedad".

\section{MATERIAL Y MÉTODO}

Tanto la estrategia general como las más importantes técnicas de investigación utilizadas en este estudio han sido de índole cualitativa. Así, se ha realizado una observación participante (en los centros de protección en los que la autora de este trabajo era una profesional asalariada, convirtiendo el espacio profesional en objeto de investigación) y a través de informes sociales, documentos personales y entrevistas informales y en profundidad, se han podido elaborar quince historias de vida de las mujeres que han residido en los centros de protección de la Comunidad Valenciana entre los años 1999 y 2012, aunque tan sólo se va a analizar las ocho historias de vida de las menores que iniciaron su trayectoria vital en el espacio o zona de vulnerabilidad.

La exclusión social es un proceso (Parrilla, 2009; Hernández Pedreño, 2008ab; Moriña, 2007; Laparra et al., 2007; Raya, 2006; Castel, 2004; Cabrera et al., 2005; Subirats, Gomà y Brugué, 2005; Subirats et al., 2004; Estivill, 2003; Bel Bell, 2002; Castells, 2001; Tezanos, 1999; Atkinson, 1998), en el que siguiendo planteamientos como los de Castel (1997), se distinguen tres espacios o zonas: de integración, de vulnerabilidad, y de exclusión social. Así, a pesar de las dificultades que supone ceñir las complejas realidades de la exclusión social a categorizaciones preestablecidas y dado que todas las historias de 
vida que se recogen en este trabajo finalizan en la zona de exclusión/institucionalización, se han clasificado según el punto de partida de la trayectoria vital en los mencionados espacios en función de dos de los clásicos ejes integración-exclusión: los ingresos económicos (bien procedan del trabajo remunerado y/o de distintos tipos de prestaciones de los Servicios Sociales -SS.SS-) y la capacidad integradora de las redes socio-familiares. A los que hemos añadido la responsabilidad respecto a las cargas familiares. Introduciendo así una perspectiva analítica de género en la que la situación de las mujeres adquiere un peso específico y se contemplen tanto los ámbitos productivos como reproductivos, de forma que sea posible desvelar cómo las situaciones de exclusión social varían según el género. Como señala Domonti (2014), el análisis de género de la exclusión social pone el acento en el hecho de que, a la hora de investigar, se ha tenido como objetivo primario visibilizar la incidencia del género en los procesos de exclusión. Pero además, cada uno de los referidos ejes o variables será analizada desde la doble y complementaria perspectiva que ofrecen, respectivamente, la familia de origen y la familia propia (porque aunque menores de 18 años, alguna de las mujeres ya la tienen).

De manera que las trayectorias vitales de las mujeres en procesos de exclusión social se situarán en la zona de: a) integración social (trabajo remunerado estable, relaciones familiares sólidas y responsabilidad respecto a las cargas familiares compartida), b) vulnerabilidad (trabajo remunerado irregular y/o prestaciones sociales, relaciones familiares débiles, conflictivas y violentas y responsabilidad de las cargas familiares sin compartir) y c) exclusión social (trabajo remunerado muy irregular o inexistente y/o dependencia de las prestaciones sociales, relaciones familiares inexistentes, conflictivas o violentas y responsabilidad de las cargas familiares sin compartir).

En el cuadro 1, se sintetizan las variables que se han utilizado para realizar la clasificación de las 15 historias de vida de las mujeres institucionalizadas en los centros de protección en la zona de integración, vulnerabilidad y exclusión social desde la perspectiva de género.

Cuadro 1. Integración, vulnerabilidad y exclusión social en las relaciones de género.

\begin{tabular}{|c|c|c|c|c|}
\hline FAMILIA & ÁMBITOS & INTEGRACIÓN & VULNERABILIDAD & EXCLUSIÓN \\
\hline \multirow[t]{2}{*}{ Origen } & $\begin{array}{l}\text { Ingresos } \\
\text { económicos }\end{array}$ & $\begin{array}{l}\text { Trabajo } \\
\text { remunerado } \\
\text { estable }\end{array}$ & $\begin{array}{l}\text { Trabajo remunerado } \\
\text { Irregular } \\
\text { Prestaciones económicas } \\
\text { de los SS.SS. }\end{array}$ & $\begin{array}{l}\text { Trabajo remunerado muy } \\
\text { irregular o inexistente } \\
\text { Prestaciones económicas de } \\
\text { los SS.SS. }\end{array}$ \\
\hline & $\begin{array}{l}\text { Redes } \\
\text { Familiares }\end{array}$ & Sólidas & $\begin{array}{l}\text { Débiles, conflictivas y } \\
\text { violentas }\end{array}$ & $\begin{array}{l}\text { Conflictivas, violentas o } \\
\text { inexistentes }\end{array}$ \\
\hline \multirow[t]{3}{*}{ Propia } & $\begin{array}{l}\text { Ingresos } \\
\text { económicos }\end{array}$ & $\begin{array}{l}\text { Trabajo } \\
\text { remunerado } \\
\text { estable }\end{array}$ & $\begin{array}{l}\text { Trabajo remunerado } \\
\text { irregular } \\
\text { Prestaciones económicas } \\
\text { de los SS.SS. }\end{array}$ & $\begin{array}{l}\text { Trabajo remunerado muy } \\
\text { irregular o inexistente } \\
\text { Prestaciones económicas de } \\
\text { los SS.SS. }\end{array}$ \\
\hline & $\begin{array}{l}\text { Redes familiares } \\
\text { y sociales }\end{array}$ & Sólidas & $\begin{array}{l}\text { Débiles, conflictivas o } \\
\text { violentas }\end{array}$ & $\begin{array}{l}\text { Conflictivas, violentas o } \\
\text { inexistentes }\end{array}$ \\
\hline & Cargas familiares & $\begin{array}{l}\text { Responsabilidad } \\
\text { compartida }\end{array}$ & $\begin{array}{l}\text { Responsabilidad no } \\
\text { compartida }\end{array}$ & $\begin{array}{l}\text { Responsabilidad no } \\
\text { compartida }\end{array}$ \\
\hline
\end{tabular}

Fuente: elaboración propia.

De esta manera, se diferenciará entre las 3 trayectorias vitales que se inician en la situación de integración social (TVI), las 8 que lo hacen en un punto intermedio o de 
vulnerabilidad (TVV) y las 4 que habitan de forma invariable en el espacio de exclusión social (TVE), como se puede ver en el cuadro 2.

Cuadro 2. Clasificación de las trayectorias vitales según el punto de partida del proceso de exclusión social.

\begin{tabular}{|c|c|c|}
\hline TVI & TVV & TVE \\
\hline Reme (HV6) & Maite (HV1) & Sonia (HV3) \\
\hline Loli (HV8) & Lola (HV2) & Karmela (HV7) \\
\hline Marian (HV15) & Teresa (HV4) & Dolores (HV11) \\
\hline & Belén (HV5) & \\
\hline & Concha (HV9) & \\
\hline & Carmina (HV10) \\
\hline & Mayte (HV13) & \\
\hline & Lorena (HV14) & \\
\hline
\end{tabular}

Fuente: elaboración propia.

Aunque como se ha señalado, dadas las limitaciones del artículo, sólo se van a analizar las 8 historias de vida de las menores que inician su trayectoria vital en la zona o el espacio social o situación de vulnerabilidad.

\section{RESULTADOS}

(HV1): Maite

Maite nace en Sevilla en 1974, su padre era un profesional de telefónica, su madre no tenía trabajo remunerado. Ella es la mayor de seis hermanos, le siguen dos chicos, una chica y los dos más pequeños que también son varones. La relación de su padre y madre con sus hijas e hijos era jerárquica, autoritaria y violenta. Ella y sus tres hermanos mayores han sido maltratados psíquicamente tanto por su padre como por su madre y físicamente por su padre.

“(...) De pequeños nos habían dado siempre palizas, a los cuatro mayores sí, ya cuando nacieron los dos chicos, ya a ellos no, hombre les reñían, si les tenían que dar un cate, se lo daban. Pero como ellos delegaron a los mayores el cuidado de los más pequeños, prácticamente los que hacíamos de padres en el día a día éramos nosotros, ellos no se encargaban de los chicos. Entonces, los chicos eso es lo que han salido ganando, no han llevado tantas palizas ni tantas cosas".

Pero además, su padre abusa y viola a Maite desde los catorce hasta los dieciocho años, cuando se marcha del domicilio familiar.

"Mi padre abusaba de mí desde los catorce años, me acuerdo de la fecha porque era desde que me vino la regla, hasta los dieciocho. Desde los catorce a los dieciocho, porque es la edad que salí". 
A Mayte le ha costado mucho poder hablar de la violencia sexual que ejercía su padre contra ella.

"Bueno, ahora no me cuesta tanto trabajo contarlo, pero antes, hombre claro, al principio, para que yo lo soltara, bueno, pasó tiempo..."

Violencia sexual o incesto al que no podía resistirse ni del que podía defenderse.

"Lo que pasa es que claro... cuando se habla de violación, se imagina uno siempre pues... la que es violada, pues... a resistirse y todo eso, yo no me podía resistir ¿entiendes? Entonces claro... para mí... incluso malo porque como no me podía resistir, era eso también... el decir: joder, es que ni me resisto. Pero es que... no es que no me resistiera, claro que yo no quería, pero ¿cómo me voy a resistir?, si tengo que aguantarle de todas maneras, o sea, es que es muy fuerte por eso. Quizá, una mujer que es violada lo pasa mal, pero luego, dentro de lo mal que lo ha pasado, a lo mejor le da el consuelo primero, de que es un extraño y después de que... me he defendido, he hecho todo lo que he podido, sin embargo... yo no he podido hacer nada".

Aunque había intentado que su madre se diese cuenta de lo que le estaba pasando, no se atreve a contárselo hasta que se marcha de casa, sobre todo, porque piensa que a su hermana le puede estar pasando lo mismo. También se enteran algunos amigos de la familia. Su padre, entonces, utiliza la estrategia de devaluar a la mensajera para que nadie la crea ni ayude, su madre se queda con el agresor.

"Cuando ya salgo se lo cuento a mi madre, por teléfono sólo. Ella lo primero que preguntó es cómo no me había quedado embarazada, eso lo primero. Entonces yo, claro, tampoco por teléfono y en una cabina no te vas a poner a explicarle, oye, mira, es que me hace esto, es que no eyacula dentro. Ni era la manera ni era el momento de hablar. Me dijo, una de dos, o es mentira, o si es verdad es porque a ti te gustaba, me lo dijo así. Pero yo sí le remarqué mucho lo de que tuviera cuidado con mi hermana, que no se lo decía porque pensara volver, que yo no pensaba volver más, sino que era por eso. Entonces ella me preguntó, "bueno, ¿y tú qué quieres que haga yo ahora?”. Yo le contesté, mira, como yo no voy a volver a mí me da igual, es tu vida, haz tú lo que quieras. De hecho, a partir de ahí perdieron muchas amistades porque se enteraron de eso. Él, después de eso, empezó a correr la voz de que yo era una prostituta, que estaba metida en tema de drogas..."

\section{(HV2): Lola}

Lola nace en Valencia en 1977, su madre ejercía la prostitución, a su padre lo ha conocido recientemente. Es la mayor de dos hermanas, la pequeña es hija de la actual pareja de su madre. Ambas vivían con los abuelos maternos hasta que la abuela enfermó de cáncer y falleció. A los 14 años se va a vivir con su madre y la pareja de ésta. La relación es muy conflictiva desde el principio, sobre todo con su padrastro, porque abusaba sexualmente de ella, por lo que sufre importantes depresiones y ha tenido que estar en tratamiento psiquiátrico. Todavía le cuesta hablar de ello sin ponerse a llorar. 
“(...) que es cuando me fui porque me dio la gana, porque hacía cosas que no eran normales... eso no te lo digo ¿vale?, porque me pongo a llorar".

A los 17 años exige a su madre que elija entre su marido y ella, pero le elige a él y Lola se marcha de casa. Su familia extensa, en principio, entiende los motivos de su huida y le dan la razón. Tanto su madre como su pareja utilizan la estrategia de devaluar a la mensajera en el ámbito familiar para que nadie crea el mensaje.

"Yo cuando me escapé, pues porque me fui de mi casa y dejé a mi madre, al principio me decían que sí, que tenía razón y tal y a los dos días me decían que era una mentirosa, que no decía la verdad. Porque mi padrastro y mi madre se fueron a toda la familia diciendo que yo claro, era una drogadicta..."

Como Lola todavía es menor de edad tiene que volver al domicilio materno. Cuando cumple los 18 años se vuelve a marchar sin tener dónde vivir por culpa de la violencia sexual que ejerce su padrastro contra ella.

\section{(HV4): Teresa}

Teresa nace en 1978 en un pueblo cercano a Valencia, es la mayor de dos hermanas. Su padre trabaja en el campo, su madre no tiene trabajo remunerado. La situación en la casa es muy conflictiva y la violencia marca su infancia y adolescencia. Su padre maltrataba física y psicológicamente, sobre todo a su madre, pero también a ella y a su hermana. Cuando la madre de Teresa no podía aguantar las agresiones se marchaba con sus dos hijas a su cercana localidad de origen donde viven sus padres, hasta que éstos fallecen. Así, y debido a la violencia de género, los cambios de domicilio y de colegio son constantes y a pesar de estar escolarizada hasta los 16 años, Teresa no consigue obtener el título de graduado escolar.

\section{(HV5): Belén}

Belén nace en 1984 en una localidad de la provincia de Castellón. Son seis hermanas/os, ella es la tercera y la otra chica la quinta, los demás son varones. Su madre tiene una diversidad funcional psíquica y frecuentes ataques epilépticos, su padre era albañil y presentaba una importante adicción al alcohol. Su domicilio familiar está situado junto al de su abuela materna que era la que tenía la tutela y se ocupa de sus seis nietas/os hasta que fallece. Tras su muerte son declarados en situación desamparo, tutelados por la administración pública e ingresadas/os en una residencia de menores de los SS.SS. en Castellón, Belén tiene nueve años. Poco tiempo después, la sección de menores de la Consellería les concede permiso para pasar los fines de semana y periodos vacacionales en casa de sus padres. Belén, por ser la hija mayor, carga con la responsabilidad de las tareas domésticas que se suponía debía realizar su madre y esto marca su infancia y juventud.

"Yo tampoco los quiero ver porque desde que nací me han amargao la vida, por las palizas, por ser criada. Sí, porque era yo quién tenía que hacerlo todo, a mí me tocaba hacerlo todo, hacer la comida, hacer todo. O sea, como una criada, por eso no quiero estar con ellos, porque me han amargao la vida. Yo qué sé, es que es muy complicao porque eso no mola, ser esclava de uno de tus hermanos es lo peor. De uno de tus hermanos o de varios como yo he sido. Yo he criao a mis hermanos pequeños cuando murió mi abuela, yo los he estado cuidando por eso los quiero 
mucho. Pero mira, a los mayores es que ya, es que es como si me amenazaran, no, si no haces esto no sales o si no haces esto no te damos dinero y no sales. Entonces por narices lo tenía que hacer y lo más bonito era que lo hacía y no me dejaban salir, me tenía que escapar. Pero lo que es mis dos hermanos mayores y mi padre no existen porque me han maltratao físicamente y lo de la cabeza, psíquicamente. Aunque yo me revolvía, eso por supuesto, uf, pues no hemos tenido movidas...”

Belén conoce al futuro padre de su hijo en la residencia y empieza a salir con él, a los tres meses está embarazada; tiene 15 años, no utiliza ningún método anticonceptivo, no tiene información sobre ellos. La relación de pareja es muy conflictiva desde el principio, las rupturas y reconciliaciones son continuas. Ello agrava el estado de ánimo de Belén que desde los 13 años dice que se quiere morir porque su vida es un fracaso. Aunque lo oculta se autolesiona, en el argot lo llaman "chinarse", lo aprende de su hermano que lo hace cuando rompe con la novia.

"Me dejó más amarga, antes de enterarme de que estaba embarazada me dejó por discutir y eso. Entonces yo me harté y me fui, cogí un cuchillo y empecé a cortarme el brazo, me corté el brazo y luego a la semana siguiente pues volvimos. Me rajé el brazo, por rabia, o sea, yo iba pensando en toda mi vida y cada cosa que recordaba cuchillazo que me metía, entre el odio y la rabia, las dos cosas".

Belén comunica el embarazo al padre de su futuro bebé, él no quiere que lo tenga y le pide que aborte o que lo dé en adopción, pero ella sí lo quiere tener. Belén es trasladada a una residencia de mujeres y con 16 años tiene a su primer hijo. La relación sigue siendo muy conflictiva, a la sección de menores llega información de que su pareja ejerce violencia física contra Belén, ella lo oculta para que no se le retiren los permisos de fin de semana ni se descarte su posibilidad de salida del centro con él cuando cumpla los 18 años.

\section{(HV9): Concha}

Concha nace en Guinea Ecuatorial en 1983, es la mayor de dos hermanas, ambas se quedan con su madre cuando sus padres se divorcian, ella tiene 4 años. Su padre intenta ganarse la vida con negocios de compra y venta y su madre se ocupa de la casa y de sus hijas. A Concha le va bien en el colegio hasta que con 8 años inicia un proceso migratorio, porque su madre la manda al Estado español con su familia extensa. En Vitoria vive una de sus tías y su abuela materna, que trabaja de interna en una casa, otra tía vive en Barcelona y otro en Valencia. El padre de Concha también se ha trasladado al Estado español y vive en Madrid. A ella la llevan primero a vivir con su tía a Barcelona, como la cosa no va bien la trasladan a Vitoria a casa de su otra tía. Concha no está a gusto, tiene que colaborar en las tareas domésticas y cuidar a su prima obligatoriamente y no le queda apenas tiempo para estudiar, por lo que empieza a ir mal en el colegio. Tampoco tiene ningún tipo de libertad, incluso tiene que pedir permiso para tomar alguna cosa de comer. Pero además, sufre malos tratos psíquicos y palizas por parte de su tía, situación que la lleva a enfermar y a desear la muerte, ha intentado suicidarse en varias ocasiones.

“Es que no vales pa' ná”, mi tía me decía, una vez, madre mía, cogió un cuchillo y quería darme, y yo le dije mátame, mejor para mí, así me alejo de vosotros. Y yo también he intentado tomarme cosas a ver si la palmaba. Yo sí, pero tía yo no sé qué 
pasa que siempre me pillaba mi abuela. Sí, desde los trece por lo menos y venga a compararme con unas y a compararme con otras, así llegue a meterme en la bulimia al final... Yo sí, y fíjate si no les interesaba nada que ni llegaron a notar que estaba bulímica yo. Y mira tuve que salir yo sola, ni psicólogo, ni psiquiatra, nada, yo sola (...). Porque no tenía ni cartilla sanitaria, tenía años caducao lo del pasaporte y ni me lo renovaron, nada, nada, ni médicos, ni papeles...

La mandan a Valencia a casa de su tío y la pareja de éste que tienen un bebé de un mes. No puede salir de casa ni tiene libertad alguna, tampoco va al colegio, su tío también la maltrata psíquica y físicamente.

"Con mi tío y con su mujer, otro igual, haciendo de niñera y de chacha, y sin una libertad, a la panadería justo debajo del patio, compraba pan y subía. Vete a comprarme esto y vete a echarme la carta, y por el balcón mirándome. Pero es que si no me dais confianza yo tampoco os la voy a dar a vosotros, y si no me dejáis un poco de libertad pues yo al final me rebelaré y saben cómo soy. En nada que me digan, si no me parece bien pues no lo hago y aunque me lleve una paliza me da igual, que luego el dolor se va".

La primera vez que sale de casa se escapa, pero vuelve. La segunda vez piensa hacer autoestop e irse lejos, entonces conoce al futuro padre de su primer hijo, inician una relación y se va a vivir con él, antes de los 18 años se separan y ella, como es menor y no tiene donde vivir, es ingresada en un centro de protección de mujeres con su hijo.

\section{(HV10): Carmina}

Carmina nace en 1970 en un pueblo de la provincia de Castellón. Es la pequeña de cuatro hermanos, los tres mayores son varones. Su padre tenía trabajo estable en una fábrica, su madre no tenía trabajo remunerado. La relación de sus padres era muy conflictiva, se separan y el padre se va de casa, Carmina tiene 9 años. Ni su padre ni su madre se preocupan de ella, que estudia hasta quinto, no termina la enseñanza obligatoria y no consigue el título de graduado escolar. A los 17 años, en una parada de la feria de su pueblo conoce a un chico y empiezan a salir juntos, al mes le propone que se vaya a vivir con él, ella acepta. A los cuatro meses de conocerse él le propina la primera paliza, ella todavía es menor de edad.

"Él me dejó sola en la parada, eso me lo había hecho muchas veces, no pude ir ni al bar a tomarme un bocadillo ni al servicio ni nada. Sólo venía a ver si había vendido algo y le daba dinero, yo le decía que no, que no había hecho nada, como no le daba, se iba. Yo estuve allí todo el día, él se emborrachó con el amigo. Sobre las seis de la tarde llegaron mis suegros. Les di el dinero, yo si me quedo en un sitio no suelo coger nada de nadie, eso es lo que tengo yo. Entonces, también vino él y vio lo que se había hecho de caja. No le había dado dinero porque sabía que era para chocolate. Él me dijo "ven que quiero hablar contigo". Voy con él hacía bajo y me dice "sabes que te digo, hija de puta, ahora te dejo aquí'. Y yo le decía no, no, e iba detrás de él como una tonta. Me vio la gente, ahí empezaron los malos tratos, empezó a darme puñetazos en el callejón, me pegó y yo detrás de él, y él "que te vayas porque si no, te pegaré más” y yo detrás de él y más me pegaba..."

(HV13): Mayte 
Mayte nace en 1976 en Rumania, es la tercera de siete hermanos, cinco chicas y dos chicos. Su madre se ocupaba de la casa e hijos y su padre tenía trabajo remunerado. Ella manifiesta haber tenido una infancia normal. Aunque señala que la relación de sus padres era buena, su padre maltrataba a su madre y aunque ésta intentó divorciarse de su padre no lo consiguió.

"La relación entre mis padres era buena, aunque a veces mi padre le pegaba a mi madre, pero en mi país esto es algo normal no es como aquí. (...) Una vez mi madre decidió separarse de mi padre, en el juicio la abogada decidió que tres hijos se quedasen con mi madre y tres con mi padre. Pero mi padre dijo que no, que él no iba a separar a sus hijos, que nos quedásemos todos con él, porque él trabajaba y no nos iba a faltar nada. El juez al oír esto le dijo a mi madre que lo mejor sería que se fueran todos juntos a casa, porque pensaba que mi padre era un buen padre, trabajador, atento, y mis padres volvieron a casa juntos y al final no se separaron”.

\section{(HV14): Lorena}

Lorena nace en Colombia en 1981, su padre era ingeniero civil y fallece en un accidente laboral cuando ella tenía 8 meses, su hermano 3 años y su madre 23 años. A partir de ese momento, su madre encuentra un trabajo remunerado y posteriormente comienza una nueva relación de pareja, tres años después inician la convivencia. Muy pronto empiezan los malos tratos, Lorena y su hermano ven a su madre sangrando en muchas ocasiones. A medida que Lorena y su hermano van creciendo no pueden soportar la situación de violencia que sufre su madre. De hecho, su hermano va a la policía a denunciar al compañero de su madre en varias ocasiones, otras interviene y su padrastro le agrede también a él, lo mismo pasaba con Lorena que, además, le pedía su madre que se separase.

"Me pegaba a mí porque yo me volví muy rebelde desde los más o menos trece años, porque yo estaba muy enfadada con mi mamá, porque yo le decía por qué no lo dejas y mi madre, pues tenía miedo y no quería..."

\section{DISCUSIÓN}

En las historias de vida de las menores que inician sus trayectorias vitales en el espacio de vulnerabilidad que acabamos de analizar, subyacen distintos tipos de violencia. Por una parte, aparece la violencia de género contra sus madres, principalmente malos tratos físicos y psíquicos, que en la mayoría de los casos se hacen extensibles a ellas. Respecto a la violencia que sufren sus madres, alguna de nuestras protagonistas dice que en su país se trata de algo normal. La normalización de la violencia es una barrera cultural que impide o dificulta a las mujeres escapar de la violencia de género (Moriana, 2014 y 2015).

Pero además de los malos tratos físicos y psíquicos contra las hijas por parte de sus padres y padrastros, también aparecen distintos tipos de violencia sexual o incesto, especialmente abusos sexuales y violaciones. Como se afirma en las historias de vida analizadas, las menores no podían resistirse ni defenderse de la violencia sexual que sufrían. Siguiendo a Ventosa y López (2007), el incesto es la forma más severa de abusos sexuales a la infancia, pues implica la distorsión de los vínculos afectivos primarios y de los roles familiares y socava profundamente la capacidad de relación. Además, se produce dentro del núcleo de 
convivencia familiar, lo que hace a la víctima especialmente vulnerable e indefensa debido a la relación de dependencia material, afectiva y cognitiva del abusador.

Así mismo, como hemos podido observar, a las mujeres les cuesta mucho hablar de la violencia sexual que han sufrido siendo menores, como señala Lyon (citado en Guillén et al., 2002), el silencio de las víctimas este tipo de violencia, entre otras razones, por sentimientos de culpabilidad o vergüenza y por miedo a las consecuencias que la declaración pueda tener para sí misma, sus seres queridos y los agresores, favorece la impunidad de los mismos. Distintos estudios apuntan que entre el 1 y el $16 \%$ de las mujeres han sufrido incesto en su contexto familiar; aunque, los métodos de recogida de información y la tendencia a ocultar la experiencia dificultan la fiabilidad de los datos (Russell, 1986, citado en Ventosa y López, 2007). Por su parte, en la mayoría de los casos de abusos sexuales a menores el abusador es un familiar directo o persona próxima a su familia. Siguiendo a Echeburúa y Guerricaechevarría (2000: 13-14, citando a McCarthy, 1992), sobre el $20 \%$ de los casos denunciados de incesto hacen referencia a padre-hija, el $15-20 \%$ padrastro-hija y el $65 \%$ restante a hermanos, tíos, hermanastros, abuelos, y novios de familiares que viven en el mismo hogar.

La violencia sexual causa a las menores importantes problemas de salud mental y depresiones. Como señala Ventosa y López (2007), las mujeres que han sufrido abuso sexual intrafamiliar en la infancia pueden presentar serios problemas de salud mental en la edad adulta, que van desde el trastorno de angustia a la depresión crónica. Pero además, la violencia sexual obliga a las jóvenes a salir de casa de forma precipitada sin tener dónde ir enseguida que cumplen la mayoría de edad. Aunque en algunos casos les cuentan a sus madres los malos tratos sexuales que sufren, o bien no las creen o bien les dicen que si es verdad es porque les gustaba y se quedan con el maltratador. Así, sus padres y madres utilizan la estrategia de devaluar a las mensajeras acusando a las jóvenes de prostitutas y toxicómanas, para que nadie las crea ni ayude. Como señala Juliano (2004), la principal función del estigma de la prostitución es controlar a las mujeres no prostitutas.

En las trayectorias analizadas también subyace el abandono de menores tanto por parte de la madre como del padre. Cabe destacar que este fenómeno cuando se produce en el entorno familiar se considera también como un tipo de violencia o trato negligente (ONU, 2006). Para algunos autores es la forma más común de maltrato (López Martín, 2007). Se define como la situación en la que las necesidades físicas (alimentación, vestido, higiene, educación, cuidados médicos, protección y vigilancia en las situaciones potencialmente peligrosas) y cognitivas básicas no son atendidas temporal o permanentemente por ningún miembro del grupo en el que convive el o la menor (Arruabarrena y De Paúl, 1999). También se ha definido el abandono infantil en referencia al fallo de los padres o de las personas cuidadoras para procurar un cuidado básico de la salud física, la supervisión, la nutrición, la higiene personal, el cultivo emocional, la educación y el alojamiento seguro (López Martín, 2007).

Por otra parte, se observan malos tratos físicos y psíquicos contra las menores por parte de su familia nuclear (padre, hermanos) o extensa (tías y tíos) para que las jóvenes realicen las tareas domésticas y de cuidado de las personas dependientes sin ningún tipo de remuneración. Por este motivo las menores llegan a afirmar que le han amargado la vida, se sentía criadas en su casas y esclavas de su propia familias.

En las trayectorias de las menores analizadas también aparece violencia de género contra ellas siendo menores, principalmente física y psíquica. Probablemente también sexual, aunque ellas quizá no son del todo consciente debido a la tendencia a creer que sus parejas tienen todos los derechos sobre sus cuerpos, lo que hace que en muchos casos este 
tipo de violencia pase inadvertida. Prácticamente ninguna menor denuncia a los agresores. Siguiendo datos de la Macroencuesta de Violencia contra la Mujer (2015), siete de cada diez mujeres que han sufrido violencia de género (el 67,8\%) nunca lo han denunciado.

Algunas mujeres están institucionalizadas en los centros de servicios sociales prácticamente toda su vida, primero en los de menores y posteriormente en los de mujeres, por lo que no es difícil entender que estén hartas y deseen su libertad (en los centros tienen que cumplir normas y horarios estrictos, además de convivir con más compañeras y ser controladas en todo momento por las profesionales), por lo que incluso ocultan los malos tratos a los que las someten sus parejas para que no se descarte la posibilidad de salir de la residencia con ellos.

\section{CONCLUSIONES}

Cabe señalar que las mujeres en procesos de exclusión social institucionalizadas que han iniciado su trayectoria vital en el espacio social de la vulnerabilidad han sufrido distintos tipos de violencia siendo menores de 18 años. Por una parte, malos tratos físicos y psíquicos por parte de sus familias para obligarlas a realizar las tareas domésticas, es decir para que asuman el rol de género. Por otra, como hemos visto en las trayectorias analizadas, además de afectarles la violencia de género contra sus madres, ellas también han sufrido distintos tipos de violencia de género, o malos tratos físicos y psíquicos por parte de sus parejas siendo menores.

Finalmente, es necesario reseñar que en las historias de vida de las menores analizadas subyacen malos tratos físicos, psíquicos y sexuales por parte de sus padres. Pero también, abandono y malos tratos psíquicos por parte tanto de sus madres como de sus padres, lo que les ha impedido terminar procesos formativos. Por su parte, los malos tratos sexuales les han provocado importantes problemas de salud mental y además, las ha obligado a salir de casa de forma precipitada sin tener dónde ir, iniciando importantes de procesos de exclusión social. Por lo que podemos decir que la violencia intrafamiliar contra las menores deviene un importantísimo factor de exclusión social específico de género. Así, la exclusión social y la violencia contra las mujeres están estrechamente relacionadas, ya que la violencia aboca a las menores a importantes procesos de exclusión social.

\section{BIBLIOGRAFÍA}

ARRUABARRENA, M. I. y DE PAÚL, J. (1999). Maltrato a los niños en la familia. Evaluación y Tratamiento. Madrid: Pirámide.

ATKINSON, A (1998). "La exclusión, la pobreza y el desempleo Social”, en J. Hills (ed.) Exclusión, Empleo y Oportunidades. Londres: Centro de Análisis de la Exclusión Social, pp. 1-20.

BEL ADELL, C. (2002). Exclusión social: Origen y características. Curso de Formación específica. Compensación Educativa e Intercultural para Agentes Educativos. Murcia: Universidad de Murcia, en http://enxarxats.intersindical.org/nee/CE_exclusio.pdf [consulta 12/03/2015].

CABRERA, P. (dir.). (2005). Nuevas Tecnologías y exclusión social. Un estudio sobre las posibilidades de las TIC en la lucha por la inclusión social en España. Madrid: Fundación Telefónica.

CASTEL, R. (2004). "Encuadre de la exclusión”, en S. Karsz La exclusión: bordeando sus fronteras. Definiciones y matices. Barcelona: Gedisa, pp. 55-86.

CASTEL, R. (1997). La metamorfosis de la cuestión social. Una Crónica del asalariado. Buenos Aires: Paidós. 
CASTELLS, M. (2001). La Era de la Información. Fin del Milenio, vol. III. México: Siglo XXI. DAMONTI, P. (2014). "Exclusión Social y Género: un análisis de la realidad contemporánea", Revista Zerbitzuan, 57: 71-89.

DELEGACIÓN DEL GOBIERNO PARA LA VIOLENCIA DE GÉNERO (2015). Macroencuesta de Violencia contra la Mujer-avance de resultados. Madrid: Ministerio de Sanidad, Servicios Sociales e Igualdad.

ECHEBURÚA, E. y GUERRICAECHEVARRÍA, C. (2000). Abuso sexual en la infancia: víctimas y agresores. Un enfoque clínico. Barcelona: Ariel.

ESTIVILL, J. (2003). Panorama de lucha contra la exclusión social: conceptos y estrategias. Ginebra: Oficina Internacional del Trabajo.

GUILLÉN, E.; ALEMÁN, C.; ARIAS, A.; DE LUCAS, F.; PÉREZ, D. (2002). "La detección de los casos de abuso sexual infantil desde los Servicios Sociales Generales: Principales dificultades y algunas sugerencias para su solución". IV Congreso de Escuelas de Trabajo Social. Los desafíos de la Violencia. Un compromiso del Trabajo Social para una sociedad más justa. Alternativas. Cuadernos de Trabajo Social, 10: 241-252.

HERNÁNDEZ PEDREÑO, M. (2008a). "Pobreza y exclusión social en las sociedades del conocimiento", en M. Hernández Pedreño (coord.) Exclusión social y desigualdad. Murcia: Universidad de Murcia, pp. 15-58.

HERNÁNDEZ PEDREÑO, M. (dir.) (2008b). Exclusión Social en la Región de Murcia. Aproximación cualitativa y cuantitativa. Murcia. Universidad de Murcia.

JULIANO, D. (2004). Excluidas y marginadas. Madrid: Feminismos, Cátedra.

LAPARRA, M.; OBRADORS, A.; PÉREZ ERANSUS, B.; PÉREZ, M.; RENES, V.; SARASA, S.; SUBIRATS, J. y TRUJILLO, M. (2007). "Una propuesta de consenso sobre el concepto de exclusión. Implicaciones Metodológicas”. Revista española del Tercer Sector, 5:15-57.

LÓPEZ MARTÍN, E. (dir.) (2007). Violencia en el ámbito familiar contra menores, mayores y personas con discapacidad. Documento de Trabajo. Serie Familia y Sociedad, 1, Madrid: CEU.

MINISTERIO DE TRABAJO Y ASUNTOS SOCIALES (2006). Maltrato infantil: detección, notificación y registro de casos. Grupo de trabajo sobre maltrato infantil del Observatorio de la Infancia. Madrid: MTAS.

MORIANA, G. (2015). "Barreras para escapar de la violencia de género: la mirada de las profesionales de los centros de protección de mujeres". Cuadernos de Trabajo Social, 28(1): 93-102.

MORIANA, G. (2014). Entre la exclusión y violencia. Las mujeres institucionalizadas en los centros de protección de mujeres de la Comunidad Valenciana. Tesis doctoral depositada en RODERIC y disponible en la dirección: http://roderic.uv.es//handle/10550/35219 [consulta 25/09/2014].

ONU (2006). Estudio a fondo de todas las formas de violencia contra las mujeres. Informe del Secretariado General, en http://www.cepal.org/mujer/noticias/paginas/1/27401/InformeSecreGeneral. pdf [consulta 1/4/2015].

ORGANIZACIÓN MUNDIAL DE LA SALUD (2002). Informe sobre la salud en el mundo: reducir los riesgos y promover una vida sana, en http://www.who.int/whr/2002/es/ [consulta 3/9/2014].

PARRILLA, Á. (2009). "¿Y si la investigación sobre inclusión no fuera inclusiva? Reflexiones desde una investigación biográfico-narrativa". Revista de Educación, 349:101-117.

RAYA, E. (2006). Indicadores de exclusión social. Una aproximación al estudio aplicado de la exclusión social. Bilbao: Universidad del País Vasco.

SUBIRATS, J.; GOMÀ, R. y BRUGUÉ, Q. (2005). Análisis de los factores de exclusión social. Barcelona: Fundación BBVA y Generalitat de Catalunya.

SUBIRATS, J.; RIBA C.; JIMÉNEZ, L.; OBRADORS, A.; JIMÉNEZ, M.; QUERALT, D.; BOTTOS, P. y RAPOPORT, A. (2004). Pobreza y exclusión social. Un análisis de la realidad española y europea. Colección de estudios sociales. Fundació La Caixa. $\mathrm{N}^{\mathrm{o}}$ 16, en https://obrasocial.lacaixa.es/de ployedfiles/obrasocial/Estaticos/pdf/Estudios_sociales/vol16_es.pdf [consulta 6/4/2015].

TEZANOS, J. F. (1999). Tendencias en desigualdad y exclusión social. Madrid: Sistemas.

VENTOSA M. y LÓPEZ, R. (2007). "Perfil clínico e intervención en salud mental con mujeres supervivientes a abuso sexual infantil intrafamiliar (incesto)", en J. Cobo Gómez (coord.) Publicación oficial de la Sociedad Española de Psiquiatría Biológica, 14(4):153-162. 


\section{Breve currículo:}

\section{Gabriela Moriana Mateo}

Profesora del departamento de Trabajo Social y Servicios Social. Directora del Máster Universitario en Género y Políticas de Igualdad. Forma parte del Instituto Universitario de Estudis de la Mujer de la Universidad de Valencia. Es especialista en análisis desde la perspectiva de género y sus principales líneas de investigación son la igualdad de género, los procesos de exclusión social desde la perspectiva de género y la violencia contra las mujeres. Algunas de sus últimas publicaciones son: Historias de vida de las menores entre la exclusión social y las violencias, en Asparkía 26: 105-123 y Violencias contra las mujeres, en Arxius de Ciències Socials, 2014, 31: 213-226. 